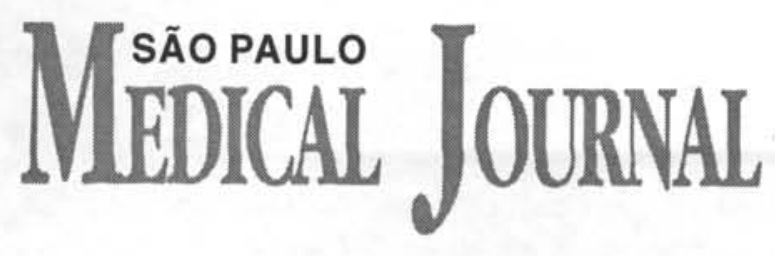

Maria de Lourdes Lopes Ferrari Chauffaille, José Tadeu Stéfano,

\title{
del 11(q23) as a prognostic factor of iron overload in refractory anemia with ringed sideroblasts
}

Disciplina de Hematologia e Hemoterapia, Escola Paulista de Medicina-UNIFESP - São Paulo, Brazil

We present the case of a patient with MDS RARS subtype with loss of part of the long arm of chromosome 11 del 11(q23). This a cytogenetic abnormality that occurs in $7 \%$ to $20 \%$ of RARS cases not related to poor prognosis. It seems that this deletion is a marker of iron overload in MDS.

UNITERMS: Myelodysplasia. Iron overload. Refractory anemia with ringed sideroblasts. Karyotype.

\section{INTRODUCTION.}

$\mathrm{M}$ yelodysplastic syndrome (MDS) is a clonal pluripotent stem cell proliferation. The term gathers together a group of disorders that show hematological cell displasia with different levels of peripheral cytopenia, generally with hypercellular bone marrow. Defective maturation is associated with the precursor cell proliferation.

Usually, patients are older than 50 years, MDS being rare in childhood and adolescence, and symptoms relate directly to cytopenia. The etiology is almost always unknown (primary MDS) but can be secondary to myelotoxic drugs like the antineoplastic ones (secondary MDS).

\section{Address for correspondence:}

Maria de Lurdes Lopes Ferrari Chauffaille

Rua Botucatu - 3andar.

São Paulo/SP - Brasil - CEP 04023-900
FAB classification has established 5 subtypes': refractory anemia(RA), refractory anemia with ringed sideroblasts (RARS), refractory anemia with excess of blasts(RAEB), refractory anemia with excess of blasts in transformation (RAEBt) and chronic myelomonocytic leukemia (CMML), though some clinical presentations do not fit into any of them, like MDS with marrow fibrosis or hypocellularity.

Around $80 \%$ of the patients present karyotype abnormalities in marrow cells, the most frequent being: trissomy 8 , loss of part of the long arms of chromosomes $5,7,9,20$ or 21 , and monossomy 7 or $9 .^{2}$ These abnormalities are of independent prognostic value. Vorhoef et al.(1991) studied karyotype prognostic importance in MDS patients and observed different survival times among patients with complex karyotype (7 months of survival) versus single abnormalities (21 months) versus normal karyotype (30 months).

Evolution follows the subtype. So, benign subtypes like RA and RARS rarely evolve into acute leukemia, and the patient remains with chronic anemia refractory to 
therapy. The subtypes RAEB, RAEBt and CMML are more aggressive in that 30 to $50 \%$ of the patients evolve into acute leukemia with mean survival of 5 to 10 months for the first two, and 20 months for CMML.

Acquired RARS is a chronic macrocytic anemia related to a disorder in heme biosynthesis, ineffective erythropoiesis without reticulocytosis and mitocondrial iron overload that leads to the presentation of more than 15 ringed sideroblasts per 100 erythroblasts. Only $10 \%$ evolve into acute myeloid leukemia (AML). Serum iron, ferritin and transferin saturation levels are high, as well as in bone marrow, as shown by cytochemical staining.

Here, the case of a patient with RARS and chromosomal abnormality del 11(q23) with iron overload is presented.

\section{CASE REPORT}

A.R., a 62 year old white female patient, first came to our hospital in November 1992 complaining of having had weakness for 3 months. She had been treated in another hospital with iron and folic acid supplementation without success. She referred the use of hair dyes and field working from childhood until 40 years old with exposure to agrotoxins.

She was in good physical condition, obese, with pallor $+++/ 4$, liver at $1 \mathrm{~cm}$ from right costal margin, unpalpable spleen, $\mathrm{Hb}=5.8 \mathrm{~g} \% ; \mathrm{Ht}=17 \%$, anisocytosis+, macrocytosis + , microcytosis + , hypocromia++ and ovalocites $+/ 4$, WBC $=3,000 / \mathrm{mm}^{3}, 2 \%$ stick, $64 \%$ segmented, $2 \%$ basophils, $1 \%$ eosinophils, $28 \%$ lymphocytes and $3 \%$ monocytes. Platelets were $460,000 /$ $\mathrm{mm}^{3}$ with macroplatelets. Hypercellular bone marrow with a granulocyte to erythrocyte ratio of $0.8: 1$. Erythroid hyperplasia (44\%) with slight dyserythropoiesis and rare nuclear budding; normoplastic granulocytic series (42.4\%) with $0.6 \%$ blasts and some hypergranular cells; mature lymphocytes (8.8\%) and hyperplastic megakaryocytic with displasia and micromegakaryocytes. Bone marrow iron was abundant and there was $41 \%$ sideroblasts, $27 \%$ of which were ringed. Bone marrow biopsy (iliac bone) had $70 \%$ cellularity with erythroid hyperplasia and granulocytic proliferation fitting the criteria for MDS diagnosis. Ham test was negative and neutrophil alkaline phosphatase score was $101(\mathrm{nl}=15-75)$. Fetal $\mathrm{Hb} 0.6 \%$.

The patient was followed up and presented a slight clinical and hematological improvement for a short period of time (Fig 1). Afterwards, she presented an episode of fever, hepatomegaly and hemolysis due to infection with hemoglobin falling to $2.5 \mathrm{~g} \%$ and an increase of indirect bilirrubin and DHL (1.7 and 1121 respectively).
Since then she has needed transfusional support (a mean of two concentrate packs every 2-3 weeks). In September 1995 ferritin was 6,500ug/1 (normal=155) and desferoxiamin was started. WBC and platelets were maintained. Bone marrow karyotype presented 46,XX,del 11(q23) (Fig. 2).

\section{DISCUSSION}

Abnormalities involving chromosome 11 band q23 such as translocations or deletions, are frequently seen in AML with monocytic involvement (M5 or, rarely, M4) or in leukemias that occur in infancy, and present $t(4 ; 11)$ with biphenotypic immunological aspect (monocytic and lymphoid). Recently, secondary AML and MDS with del

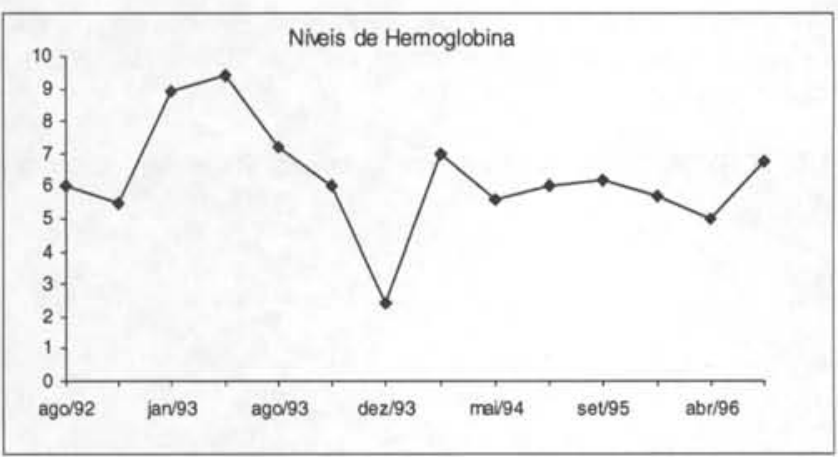

Figure 1 - Shows hemoglobin levels $(\mathrm{g} \%)$ at different follow up times (dates). Soon after diagnosis there was a short-term improvement. In December 93 there was a hemolysis episode. Afterwards the patient was in need of blood transfusions.

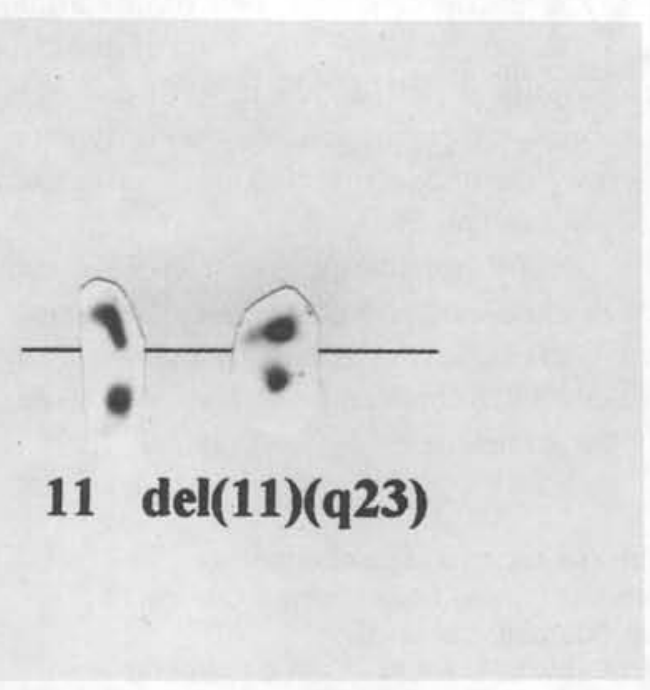

Figure 2 - Normal chromosome and del 11(q23) (arrow). 
$11 q$ in patients previously exposed to epipodophyllotoxins have also been described. ${ }^{3}$

del 11q has been described in different MDS subtypes, though it is more frequent among RA and RARS. Musilova et al. have found $13.8 \%$ del $11 \mathrm{q}$ in RA and $9.9 \%$ in MDS .

It seems that around $30 \%$ of RARS patients have chromosomal abnormalities and del $11 \mathrm{q}$ is found in $7 \%$ to $20 \%$ of these cases. Many works show different break regions in chromosome 11 , from q14 to q23. Thus, ferritin $\mathrm{H}$ chain gene located at 11q14 would not always be involved in these abnormalities. Mecucci et al. (1987) observed that del 11q was related to bone marrow iron overload and to an increase in ringed sideroblasts, among 13 patients with MDS retrospectively studied.

Considering that the patient received 90 red blood cell transfusion packs and that each one contained from
200 to $250 \mathrm{mg}$ of iron, resulting in an iron accumulation equal to $22,500 \mathrm{mg}$, such a high ferritin level is not justified. Now, if each lug/L of serum ferritin is equivalent to $8 \mathrm{mg}$ of stored iron, the $6,500 \mathrm{mg} / \mathrm{L}$ found would mean $52,000 \mathrm{mg}$ of iron, ie effectively more than twice the amount administered by transfusions. However, this could be justified by the chromossomal abnormality that predisposes to iron overload. It should also be recalled that at diagnosis, the patient had bone marrow iron overload demonstrated by Perls staining. ${ }^{4}$

The present report describes a clinically typical MDS RARS case with an unusual acquired karyotypic abnormality that predisposes to non random iron overload. Future molecular studies must be done to identify its meaning since other hematological disorders have the same cytogenetic alteration.

\section{RESUMO}

Apresentamos o caso de paciente com Síndrome Mielodisplásia (SMD) sublito Anemia Refratária com Sideroblastos em Anel (ARSA) com perda do braço longo do cromossomo 11 [del (q23)]. Trata-se de alteração citogenética que ocorre entre 7 e $20 \%$ dos casos de ARSA não se correlacionando a mau prognóstico, ou seja, evolução para leucemia aguda. Aparentemente, esta deleção é um marcador de sobrecarga de ferro na SMD.

\section{REFERENCES}

1. Bennet, JM; Catovsky, D; Daniel, MT; Flandrin, G; Galton, DAG; Gralnick, HR; Sultan, C: Proposals for the classification of myelodysplastic syndromes. British J Haematol 1982 51:189-199.

2. Heim, S: Cytogenetic findings in primary and secondary MDS. Leukemia Res 1992 16(1): 43-46.
3. Chauffaille, MLLF; Yamamoto, M; Odone, FV; Almeida, MT; Maluf Jr, P; Cristofani, LM; Kerbauy, J; Raimondi, SC: A t $(9 ; 11)$ translocation in childhood acute myeloid mixed leukemia . São Paulo Med Journ 1996 114(2):1127-30.

4. Smadja, N; Krulick, M; de Gramont, A; Brissaud, P; Debray, $\mathrm{J}$ : Acquired idiopathic sideroblastic anemia and terminal deletion of chromosome 11. Cancer Genet Cytogenet 1985 16: $275-278$. 